
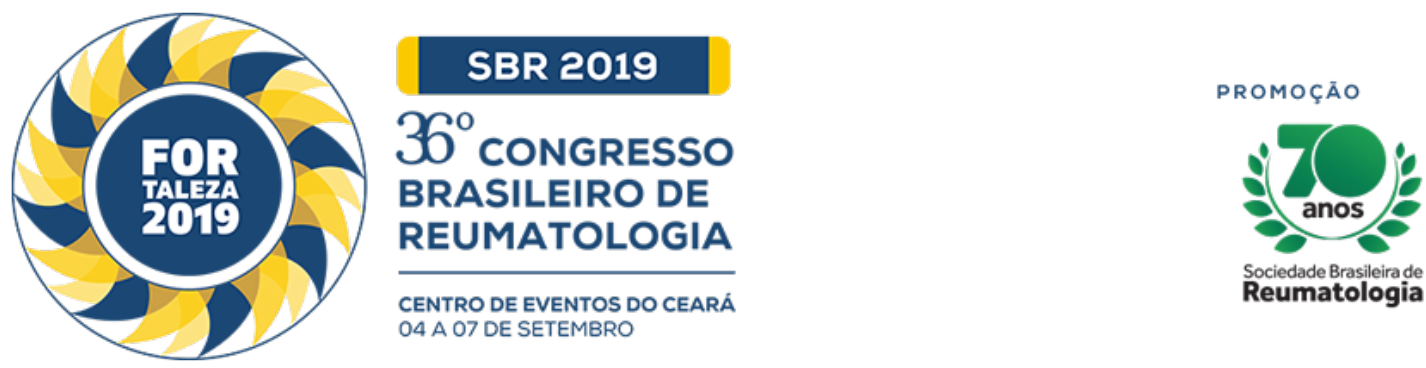

\title{
MICROSCOPIC POLYANGIITIS: CHALLENGES OF DIAGNOSIS AND TREATMENT
}

Renata Sartor Fachinelli (UNIVATES, Lajeado, RS, Brasil), Jussara Marilu Bohn (UNIVATES, Lajeado, RS, Brasil), Cláudia Monfron Rocha (UNIVATES, Lajeado, RS, Brasil), Amanda Pacheco Alves (UNIVATES, Lajeado, RS, Brasil), Jaqueline Schnorr (UNIVATES, Lajeado, RS, Brasil), Igor Minasi Stankevicius (UNIVATES, Lajeado, RS, Brasil)

\section{BACKGROUND}

Microscopic polyangeitis (MPA) is a systemic, inflammatory, and necrotizing vasculitis that predominantly affects small vessels of multiple organs. The initial clinical manifestations are: fever, arthralgia, myalgia, fatigue and / or loss of appetite. As the disease progresses, $90 \%$ of patients have renal involvement with necrotizing and crescentic pauci-immune glomerulonephritis that may have a rapid and progressive course if not treated immediately. Pulmonary is common and manifests itself with symptoms such as cough, dyspnea or hemoptysis. The most serious manifestation is combined pulmonary and renal disease (pulmonary-renal syndrome). Treatment consists of three phases: induction of remission, maintenance of remission and treatment of relapses.

\section{CASE REPORT}

D.M.M.C., a 70-year-old white patient, retired teacher, hypertensive, ischemic heart disease (3 stents), dyslipidemic, type 2 diabetic, with hypothyroidism, abdominal aortic aneurysm and diverticular disease. Patient sought care with complaint of diffuse pain for 2 months, also presenting asymmetric arthritis, anemia, myalgias, paresthesias and asthenia. Several laboratory tests were requested, highlighting the results of p-ANCA 1; 640 reagent, anti-MPO reagent 70, creatinine $5.6 \mathrm{mg} / \mathrm{dL}$ and proteinuria. Biopsia renal revealed sclerosis and formation of histopathological appearance, together with clinical data and immunofluorescence, compatible with pauci-immune vasculitis of small vessels, corroborating the hypothesis of microscopic polyangiitis. She used methylprednisolone $1 \mathrm{~g}$ for 3 days after rituximab $1 \mathrm{~g}$ followed by another $1 \mathrm{~g}$ two weeks later. Then $80 \mathrm{mg}$ of prednisone per day and started Azathioprine $150 \mathrm{mg}$ per day. With this therapy, the patient's renal function improved, creatinine decreased from 5.6 $\mathrm{mg} / \mathrm{dL}$ to $2.5 \mathrm{mg} / \mathrm{dL}$. However, the patient started to present seizures (due to cerebral vasculitis evidenced in skull MRI) therefore, was initiated medication for these seizures. Subsequently patient presented intolerance to azathioprine treatment, requiring a change in mycophenolate mofetila 500mg $4 \mathrm{x}$ daily.

\section{CONCLUSION}

The diagnosis of MPA is supported in clinical findings, laboratory tests and renal biopsy or pulmonary characteristics. Often, the patient's clinical practice is nonspecific and the late diagnosis ends up delaying the appropriate treatment of the pathology, can lead to significant losses of renal and pulmonary function of the patient. In addition, as evidenced in the case, many patients are slow to respond or do not present significant responses to first-line medications, making treatment even more difficult. Therefore, it is very important to know pathophysiology, clinical manifestations, diagnosis and treatment of the disease in suggestive cases and not to delay treatments. 